\title{
Pierre Janet And Dissociation: The First Transference Theory and Its Origins In Hypnosis John Ryan Haule \\ www.jrhaule.net
}

This article was published in the American Journal of Clinical Hypnosis 29(2) (October, 1986): pp. 86-94.

\begin{abstract}
This paper describes Pierre Janet's pioneering work in the area of hypnosis which was based on suggestion and dissociation. Janet was the first to describe somnambulism as a phenomenon whereby two or more states of consciousness are dissociated by a cleft of amnesia and seem to operate independently of one another. Janet's early understanding of rapport also had roots in dissociation in that the patient seemed unable, due to dissociative restriction of the conscious field, to perceive anyone other than his own therapist. The implications of this dissociated conscious field for treatment led Janet to provide structure in therapy by assigning tasks and to mirror the patient's experience rather than to confront it. These techniques are important even today in the treatment of dissociated states.
\end{abstract}

The French hypnotist Pierre Janet (1859-1947) is the source for most of the dissociation theory to be found in the writings of C. G. Jung (1946/1966). Janet began his career as a philosopher, who used hypnosis to explore the dissociative propensities of the human mind. Following his doctoral dissertation in philosophy, he rapidly completed a medical degree and, with the sponsorship of J. M. Charcot, opened a laboratory at the Salpêtrière in Paris, where he continued his research into the nature and treatment of dissociative conditions. Hypnosis continued to be his investigative tool and therapeutic intervention of choice because it was, in his view, a form of dissociation. "Hypnotism may be defined as the momentary transformation of the mental state of an individual, artificially induced by a second person, and sufficing to bring about dissociations of personal memory" (Janet 1919/1976, p. 291). "Dissociation" is the key word in the definition; he means the phenomenon that we presently see as diagnostic of multiple personality, that is, the simultaneous development of subpersonalities, parallel memories, in complete ignorance one of another.

Janet is also the nearly forgotten founder of the analytic tradition in psychology. Breuer and Freud (1895/1957, p. 12) credit him and other Parisian dissociationists with some of the fundamental discoveries which made their Studies on Hysteria possible. Although he was born 3 years after Freud, Janet's reputation as a psychological investigator was already more than a decade old when Freud published The Interpretation of Dreams. Probably two factors concerned with style more than anything else account for the nearly century-long eclipse which has dimmed Janet's influence upon twentieth-century psychology. The first of these is Janet's stubborn nineteenth-century belief in the triumph of careful, plodding, scientific investigation. His style is dry, his images often very mechanical, and as Ellenberger points out (1970, p. 408), he did not cultivate a troop of disciples to champion his methods and principles. The other factor is Janet's faithfulness to hypnosis, which had come into vogue around 1880 and then passed again into disrepute shortly after the turn of the century. Janet learned very early in his career the "contaminating" side effects of suggestion and, therefore, became very careful to imitate Pasteur (he liked to say) and keep 
his "cultures isolated." It was not without some bitterness, therefore, that he finally gave up his attempts to convince the world of psychology that hypnosis was a very powerful model and tool for investigation and therapy: "Hypnosis is quite dead until the day of its resurrection" (Janet, 1919/1976, p. 203).

Because of his dry style and because he almost never discusses a case fully from start to finish, it is possible to read a great deal of Janet's voluminous output (15,000 published pages according to Schwartz, 1951, p. 31) without fully appreciating his sensitivity to the emotional intensity of the rapport and the effects it may have upon the patient. For example, he might argue that Celestine, "a robust country girl ... (who) upsets the beds, changes their places, carries about with one arm, heavy wooden arm chairs" still cannot score above 10 on the dynamometer, an instrument for measuring the strength of arms and hands. Janet himself scores 50 although he is unable to lift beds and chairs. He ascribes the discrepancy in her demonstrations of strength to the dissociative effects of "trying to concentrate, to pay attention, to use personal will" (Janet, 1892, p. 164f). He never discusses the possibility that being called upon to perform an experiment may involve aspects of rapport; for example, it may give Celestine an opportunity to prove she is sick and needs Janet's close attention. About a quarter of a century later, Janet makes similar observations about Lydia, in spite of his explicit recognition of the importance of rapport (or "influence") in his treatment of her case. Indeed, he goes so far as to attribute the incompleteness of Lydia's cure to their failure to resolve the rapport: "Manifestly we have to do with a morbid habit" (Janet, 1919/1976, p. 1203). She will not get well because she cannot give up her dependency.

Given this inconsistency, Janet's accurate, detailed descriptions of the rapport are particularly surprising. He describes it variously as "influence," "adoption," and "electivity." In rapport, the patient has "adopted" the therapist as the axis of his universe.

We have to assume that at a certain moment in their treatment the patients have formed in their minds this special tendency towards a specific person, towards the person who was specially interested in them. We can speak of the moment, of this remarkable action as an "act of adoption" (Janet, 1919, p. 1154).

Because of this dissociative mechanism, the patient declares that his therapist is "the only person in the world able to understand him" (Janet 1919/1976, p. 1155). Janet calls this "a strange illusion," for "it is by no means certain that we do understand them." Rather, their act of adoption means "that they themselves have made up their minds to talk seriously" (Janet, 1919/1976, p. 1156).

Janet had recognized this phenomenon already in the late 1880's; he argued with Binet, who believed that Janet's greater success with Lucie than any other hypnotist was due to the greater intensity of Janet's suggestions. Janet insists that "It is due to the quality and not the intensity" of the suggestion. Specifically, it is the quality of the command's being tied to the person of Janet himself (1889/1973, p. 185). Rapport, in this early period of Janet's career, was seen as a kind of a "negative hallucination" for everything but the hypnotist. It is as though the patient is "anaesthetic" for all sensory phenomena except the person, voice, and commands of the therapist. In the dissociation-generated sensory void in which the hysteric or "somnambulistic" finds himself, he (unconsciously) "elects" to perceive the hypnotist. 
In his 1896 address to the International Congress of Psychology (published in 1898/1925), Janet says that many of these facts were already known to "the old magnetizers" (citing Bertrand, Dupotet, Charpignon, Noizet, and Despine d'Aix, whose books were published 40 to 80 years earlier). These earlier researchers were in agreement that rapport is characterized by (a) the patient's inability to tolerate contact with any but "his own" hypnotist, (b) the patient's "own" hypnotist being the only individual who could "put him to sleep," and (c) the patient's inability, due to the dissociative restriction (rétrécissement) of his conscious field, to perceive anyone other than his own therapist.

Janet referred to the hypnotic process as "influence somnambulique." Before 1900, Janet saw "somnambulism" as the essential condition, of which hysteria, hypnosis, multiple personality, and spiritualism were variations. The word somnambulism meant far more than sleep walking, having been expanded to include any kind of activity pursued while in a dissociated condition. Sleep walking was an instance of somnambulism because the activity which usually belongs to ordinary consciousness (walking) is pursued while the individual's consciousness is inhabiting a dreamscape. Similarly, automatic writing was somnambulistic because the writing was done with one part-personality while another, in complete ignorance of the first, might be engaged in a conversation with the experimenter. Somnambulism, therefore, was understood to be a phenomenon whereby two or more states of consciousness, dissociated by a cleft of amnesia, operate with seeming independence of one another. Hysteria was a pathological form of somnambulism in which dissociation appears autonomously for neurotic reasons, and in such a way as to adversely disturb the individual's everyday life. Hypnosis was "artificial somnambulism," dissociation induced by a therapist for experimental or therapeutic purposes, a deliberate imitation of hysteria. Multiple personality was a somnambulistic condition in which two or more dissociated states are strikingly distinct in behavior, mood, and intention, and in which one or several of the states are amnesic for one or more others. Finally, spiritualism was a kind of semi-voluntary somnambulism which involved, in addition, the attribution of causality to putative bodiless agents external to the individual.

In hypnosis, the therapist attempted to use hypnosis to manipulate the somnambulistic condition, the dissociation, to have some "influence" over it. Janet distinguished three phases of "influence somnambulique." First, immediately upon awakening from the hypnotic trance, the patient experiences a period of fatigue which usually lasts an hour or 2 but sometimes as long as 2 days. In the second phase, the period of somnambulistic influence proper, the patient enjoys apparent health and well-being, and is free of spontaneous hysterical attacks for several days or even weeks. During this time, all the usual symptoms of hysteria are alleviated: the restriction of consciousness; the reduction of visual and other sensory fields; the loss of the ability to work, read, write, enjoy; indeed, the very ability to make decisions and act upon them. Apart from the temporary nature of this phase, the main indication that a complete cure has not been effected is the patient's preoccupation with the person of his hypnotist ("la pensée persistante de l'hypnotiseur

Janet describes the patient as having sentiments and thoughts about the hypnotist which he has never had before, a mixture of fear and affection, sometimes with hallucinatory images. Such phenomena are not found in patients who have been hypnotized only rarely or who have been hypnotized by a large number of hypnotists (Janet 1898/1925, p. 452f). In short., it represents an intense relationship with the therapist, precisely the kind of situation 
in which "transference" phenomena are most likely to appear. Furthermore, Janet deems a rapport of this kind indispensable for the cure.

\begin{abstract}
But for my part, I have not seen grave hysterical symptoms of long duration cured without an education of the subject within which these phenomena of influence occupy a preponderate place; and the subjects who do not present such phenomena of influence do not succeed in profoundly transforming themselves (Janet, 1898/1925, p. 452).
\end{abstract}

In the third phase, which Janet calls " la periode de la passion somnambulique," theapparently curative effects of the hypnotic influence have disappeared and the original symptoms have returned. In addition, however, the patient now has a great longing to be "put to sleep" (artificially dissociated) and is obsessed by the thought of "his own" hypnotist. Since Freud, we can hardly read such descriptions without thinking of the sexual libido. Indeed, Janet himself says, "In all these cases, what is involved is a kind of love, but it must be emphasized that it is a very special kind which is involved" (Janet, 1898/1925, p. 465f).

He held it "completely insufficient" to identify this love with genital, erotic love. Sometimes it is filial, maternal, or respectful; sometimes it is filled with a great deal of fear; and sometimes romantic love for another coexists with hypnotic passion in a single individual without confusion (1898/1925 p. 457). Still, the examples he gives are very suggestive of erotic love: a non-hysterical woman who "needs" her lover to "direct" her; a man "directed" by his mistress; a woman with a florid hysterical history whose symptoms completely disappeared between the ages of 25 and 32 when she was living with a lover; a woman dependent on an aged nun; and a woman dependent on her son. The last two cases surely do not exclude the erotic element. Janet, himself, only goes so far as to claim it "seems much reduced."

In order to interpret these observations, it would be worthwhile to identify the patient population which Janet studied. His categories of somnambulistic, psychasthenic, and neurasthenic are no longer in use. But it seems likely that most of his patients who were capable of hypnotic "influence" (dissociation) and "passion" manifested traits which today would lead the diagnostician to consider such labels as "narcissistic" and "borderline." Binswanger (1958, p. 332), who worked with Bleuler and Jung at the Burghölzli mental hospital in Zurich in the first decade of the twentieth century, tells us that both of his mentors, the recognized experts in the field, considered that "the majority of Janet's cases must be considered schizophrenic." Certainly the cases Janet describes as too "depressed" or "exhausted" to be capable of being influenced (Janet 1919/1976, p. 1159-67) suggest the affective inaccessibility of the schizophrenic. But the patients discussed in this essay, the ones of whom Janet says, "The director is to some extent an artificial parent or an artificial friend" (Janet, 1919/1976, p. 1187), seem likely to have been narcissistic or borderline individuals. An additional indication along these lines would be the ambivalence and hostility Janet observes in them: "It is when the subject has the greatest need of the director, when he most urgently desires to see the director again, that he is filled with doubts and obsessions antagonistic to the guidance" (Janet, 1919/1976, p. 1185).

There is no denying Janet's Victorian delicacy. He frustrates us again and again with vague allusions to his patients' histories, obsessions, fantasies, and the like. Often we who have been trained in the image-oriented philosophies of Freud and Jung believe that if only Janet had revealed the shameful secret lurking at the center of the patient's pathology, we 
would be able to form a dependable diagnosis and also get our hands on Janet's elusive therapeutics. Yet, we may be wrong in this bias. It may well be that there is no "trauma" and nothing particularly to be remembered. Kohut's views (1984) would be compatible with this. If these patients are narcissistic personalities, their passionate rapport with Janet may be for them an experience of profound "empathy." Having missed the right kind of "mirroring" love in their parents, they may have found in Janet's attentive, caring regard some degree of what Kohut calls "optimal frustration."

Such a point of view might have been defensible in detail had not Janet's will required the destruction of his more than 5000 voluminous case histories. He was so conscientious -very possibly compulsive--in writing down absolutely everything his patients did and said that they came to know him as "Dr. Pencil" (Schwartz, 1951, p. 29). As we know from our own patients, writing down what they tell us can well be seen as attesting to the importance of what they say and feel, although in some cases it may become a screen for the therapist to hide behind. Janet's "philosophy of the pencil" quite emphatically suggests that his writing would have been empathic and affirming.

For us an experimental psychology is a very simple matter: it consists above all in knowing one's patient well -- in his life, his schooling, his character, and his ideas -- and to be convinced that one knows him not enough. Then one must put that person in simple and specific circumstances and note accurately what he will do and say. To examine the acts and words is surely the best means to get to know an individual, and we consider it neither useless nor fastidious to write down word for word the ramblings of an insane person (Janet, 1891/1925, p. 67).

Evidently this was Janet's technique with every one of his patients. In addition, however, it is clear that, dispassionate as the above account may sound, he was also very much emotionally attuned to his patients. Although he was a very shy, aloof, aristocratic man, Janet surprised one of Kraepelin's students with this declaration: "I believe those people (the psychotics) until it is proven to me that what they say is untrue . . you see these people are persecuted by something and you must investigate carefully to get to the root" (Ellenberger, 1970 , p. 351). The fact that there is no place in his psychology for that "persecuting" something (no Freudian id or superego, no Jungian shadow) does not prevent Janet from engaging with the patient. He tells us (Janet, 1919/1976, p. 1163) that a relationship of "influence . . . cannot possibly be established" without spending a great deal of time alone with the patient. "If you wish (the patient) to adapt himself to your personality, begin by adapting your own personality to his" (Janet, 1919/1976, p. 1170).

These glimpses of Janet's attitude toward and practice of psychotherapy seem to me to be eminently in harmony with what Heinz Kohut has advanced as the essential element in any "psychoanalytic cure":

The analyst's communication to the patient of his more or less correct understanding of the patient's inner life is optimally frustrating ... It is frustrating because, despite the analyst's understanding of what the patient feels and his acknowledgement that the patient's upset is legitimate, . . . the analyst still does not act in accordance with the patient's need. . . . It is optimally frustrating because the communication is still in compliance with the patient's need -- . .. an empathic bond is established ... that substitutes for the de facto fulfillment of the patient's need (Kohut, 1984, p. 102f; italics in the original).

Kohut is convinced that it is not only "Kohutians" who cure via optimal frustration. All analysts cure that way, even Freud, although he had not the advantage of Kohut's 
writings to show that it was not his explanations which effected the cure. All cures take place by way of empathy. Janet seems to have arrived at similar conceptions, even though they do not explicitly dominate either the theory of hypnosis or the theory of psychasthenia. For Janet they are apparently matters of common sense springing from the existential demands of human relationship.

Whereas Kohut's concern is to describe a mechanism for the curing process, and Janet's researches -- especially in the first 30 years of his career -- focus on the dissociated states attained by his patients, particularly important is the state he refers to as "complete somnambulism," the paradigm for what the Paris school of hypnosis hoped to achieve. Subjects capable of attaining the state of complete somnambulism were rare; indeed, Janet likened the quest for the perfect patient to the alchemists' search for the philosophers' stone (Janet, 1919/1976, p. 84). His brother Jules came near to finding such a patient in Marceline, whom Pierre describes extensively (Janet, 1910, 1919/1976, p. 798-817; 1892/1977, p. 433-35). In 1887, at the beginning of her treatment, she was anorectic nearly to the point of death, anaesthetic over the whole surface of her body, nearly deaf and blind, able to speak only with great difficulty, and seemingly stupid. After spending about 10 days inducing hypnotic trance using Pierre's methods, Jules was able to achieve in Marceline a state very close to complete somnambulism in which her symptoms disappeared and she was able to eat and gain weight. Upon awakening from the trance, however, she always resumed her pathological state. Continued failure to manage to transfer gains made in the hypnotic state to the "waking" state led Jules Janet to experiment with leaving her in trance for days at a time. This resulted in an improved but still unsatisfactory condition wherein Marceline had to be reinduced into complete somnambulism every few days and with the irritating complication that now when she returned to her debilitated state she could not remember the increasingly extensive periods of time spent in complete somnambulism. After 2 years of such treatment, Jules turned Marceline over to his brother Pierre for treatment so that he could concern himself with surgery and microbiology. Pierre Janet tells us nothing more about it, so that we are left to wonder how much this career change may have resembled Josef Breuer's sudden vacation to escape the passionate rapport of Anna 0. Three years later, Marceline was at her peak of good health, requiring to be reinduced into complete somnambulism only once every 5 or 6 weeks. In succeeding years, however, her condition worsened until in 1899 she was having relapses 2 or 3 times a day.

Janet refers to Marceline as "une Félida artificielle," a reference to Azam's famous patient from the 1860's, "Félida X, who spontaneously passed from a debilitated personality to a fairly healthy one and back again. As the years went by, the healthier personality predominated more and more. Felida X was the "philosopher's stone" of the Paris school of dissociationism, for her story proved that a healthy personality may reside within the neurotic, alongside or below the pathological personality(s). Janet's "artificial" Félida, however, became pathologically addicted to her relationship with her hypnotist. When he tried to diminish this by holding less frequent and shorter sessions, she began to starve herself even more (Janet, 1910, p. 344). A similar situation occurred with the patient Janet calls Irène, who at one point seemed to have been cured of hysteria through complete somnambulism but reappeared 6 years later with a less debilitating but more persistent neurosis (Janet, 1919/1976, passim).

The stories of the imperfectly complete somnambulistics, Marceline and Irène, show a 
rather typical three-stage development: an opening phase of rapport building, a phase of somnambulistic influence in which the symptoms disappear for days or weeks at a time, and an addictive passion somnambulique in which the need for direction is so strong that the patient's neurosis requires more and more frequent and lengthy sessions.

From this it seems evident that the real "philosopher's stone" in Janetian psychology is not the perfect patient, the "artificial Félida," but rather the perfect rapport. Clearly, he had hoped to cure Marceline and Irène solely by means of inducing in them a profound state of hypnotic trance. The notion of "complete" somnambulism implies that the dissociated individual has a core personality which is whole. This healthy core can be reached when the patient trusts in and submits completely to the hypnotherapist. He does not direct her to outer activities but rather inwardly to her own healthy self. Her submission, the crucial element in the transformation, cannot be won by any means except through a powerful, affect-laden rapport which closely resembles erotic love,

Janet's explanation for his failures with these patients is that the primary cause of the rapport, the morbid need to be directed (besoin de direction), isa two-edged sword. On the one hand, no cure is possible without the rapport it makes possible. But on the other hand, the need to be directed is itself a primary symptom of the disease, which disappears when the patient is cured. When the need for direction cannot be overcome, Janet locates the explanation in the patient's "lack of will." "They ardently desire to make a resolution, but they are not capable of willing it. Thus, they come to demand that another person make the act of will for them" (Janet, 1898/1925, p. 470). This notion of lack of will, inability to decide, became the central concept in Janet's writing around the turn of the century. He elaborated it into his theory of "psychasthenia," a psychological weakness whereby the individual is unable to mobilize or utilize his energy in order to perform efficient, well-adapted activities. The theory was first set down extensively in the two-volume work Obsessions et la Psychasthénie, in 1903.

If the patients had not the will, Janet hoped to raise their effective psychic energy (tension de la force mentale) so that they would be capable of performing acts such as decision-making which had formerly been impossible for them. Rapport is no less essential in this new notion of therapy. In this second period of his work, extending from the turn of the century to his death in 1947, Janet sees the primary aim of therapy as helping his patients to become capable of higher orders of activity. For this, their energy must be conserved and used wisely, and they have to learn to perform acts which had formerly been impossible for them. This latter goal requires that their latent stores of energy be roused and used efficiently. In practice, excitation therapy consists in (1) simplifying the patient's life by removing him from situations and people which drain his energy reserves, and (2) assigning a progressive set of tasks designed to improve the patient's effective use of his energy, to improve his living skills. Most of this latter task takes the form of "moral guidance" -- yet another species of "influence." (Cf. last three chapters of Janet, 1919/1976). "The main desire of the medical moralizer is to make his patient perform actions, lofty and noble actions, which will require attention and effort, thus developing will-power and moral energy" (Janet, 1919/1976, p. 121).

Such notions of "moral guidance" and "medical moralizing" may at first seem very far afield from our modem conceptions both of the analytic tradition and of hypnosis. 
Nevertheless, the theories and methods of psychoanalyst and hypnotist Milton Erickson are quite compatible with those of Janet. Whereas Janet seems to have believed that he used hypnosis less and less as his career progressed, an Ericksonian, expanded view of hypnosis dispenses with the ritual of trance-induction as essential to the hypnotic process. Consequently, Erickson and his followers could subscribe wholeheartedly to Janet's guidelines for adapting his own way of thinking to that of the patient: "Our intervention needs to be masked; we must lead them (the patients) to believe that the decisions come from themselves, must allow for them to reap the full benefits of the work in hand" (Janet, 1919/1976, p. 546).

\section{References}

Binswanger, L. (1958). The case of Ellen West. In R. May, E. Angel, \& H.F. Ellenberger (Eds.), Existence: A new dimension in psychiatry and psychology (pp. 237-364). New York: Simon \& Schuster.

Breuer, J. \& Freud, S. (1957). Studies in hysteria. J. Strachey (Ed. and Trans.). New York: Basic Books. (Original work published in 1895).

Ellenberger, H. F. (1970). The discovery of the unconscious: The history and evolution of dynamic psychiatry. New York: Basic Books.

Janet, P. (1910). Une Félida artificielle. Revue Philosophique, 69(l), 329-357, 483-529.

Janet, P. (1925). Etude sur un cas d'aboulie et d'idees fixes. In Névroses et idées fixes, (Vol. 1, pp. 1-68, 4th ed.). Paris: Alcan. (Original work published in 1891).

Janet, P. (1925). L'influence somnambulique et la besoin de direction. In Névroses et idées fixes, (Vol. 1, pp. 423-480, 4th ed.). Paris: Alcan. (Original work published in 1898).

Janet, P. (1973). L'automatisme psychologigue. Paris: Société Pierre Janet. (Original work published in 1889).

Janet, P. (1975). De l'angoisse a l'extase: Etudes sur les croyances et les sentiments. In 2 vols. Paris: Société Pierre Janet. (Original work published in 1926, 1928).

Janet, P. (1976). Les obsessions et la psychasthénie. In two vol., Vol. 2 in collaboration with F. Raymond. New York: Arno. (Original work published in 1903).

Janet, P. (1976). Psychological Healing: A historical and clinical study. 2 vols. E. \& C. Paul (Trans.). (Original work published in 1919)

Janet, P. (1977). The mental state of hystericals. In D.N. Robinson (Ed.), C.R. Corson (Trans.), Significant Contributions to the History of Psychology, Series C, Medical Psychology, Vol. 11. Washington, DC: University Publications of America. (Original work published in 1892).

Jung, C.G. (1966). The psychology of the transference. In H. Read, M. Fordham, F. Adler, \& W. McGuire (Eds.). R.F.C. Hall (Trans.). The collected works of C.G. Jung (Bollingen series). (Vol. 16, pp. 163-323). Princeton, NJ: Princeton University Press. (Original work published in 1946).

Kohut, H. (1984). How does analysis cure? A. Goldberg \& P. Stepansky (Eds.) Chicago: University of Chicago Press.

Schwartz, L. (1951). Die neurosen and die dynamishe psychologie von Pierre Janet. Basel: B. Schwabe. 